\title{
Novel Compact UWB Band Notch Antenna Design for Body-Centric Communications
}

\author{
Sk Raziul Ahasan ${ }^{1}$, Kaisarul Islam ${ }^{1}$, Mohammad Monirujjaman Khan ${ }^{1, *}$, Mehedi Masud ${ }^{2}$, Gurjot \\ Singh Gaba ${ }^{3}$ and Hesham A. Alhumyani ${ }^{4}$
}

\footnotetext{
${ }^{1}$ Department of Electrical and Computer Engineering, North South University, Bashundhara, Dhaka, 1229, Bangladesh

${ }^{2}$ Department of Computer Science, College of Computers and Information Technology, Taif University, P.O. Box 11099, Taif, 21944, Saudi Arabia

${ }^{3}$ School of Electronics \& Electrical Engineering, Lovely Professional University, Punjab, India

${ }^{4}$ Department of Computer Engineering, College of Computers and Information Technology, Taif University, P.O. Box 11099, Taif, 21944, Saudi Arabia

${ }^{*}$ Corresponding Author: Mohammad Monirujjaman Khan. Email: monirujjaman.khan@northsouth.edu; monirkhan.qmul@gmail.com Received: 18 April 2021; Accepted: 24 May 2021
}

\begin{abstract}
This research analyzes and implements an innovative and tiny ultrawideband (UWB) antenna with band-notched features for body-centric communication. The shape of the designed antenna looks like a 'swan' with a slotted patch. Computer Simulation Technology (CST) is used to assess and investigate the performance of this antenna. With a band notch, this antenna can prevent interference from Wireless Local Area Network (WLAN) (5.15-5.825 GHz) and Worldwide Interoperability for Microwave Access (WiMAX) (5.25-5.85 GHz) systems. At first, the performance parameters like return loss response, gain, radiation patterns, and radiation efficiency of this UWB antenna are evaluated. After that, the human body effects on the antenna performance of the antenna are also examined to place the antenna at various distances away from 3-layers of phantom body model at different frequencies. All the on-body performance parameter results are compared and analyzed with free space performance parameter results. Lastly, by changing patch slot length and ground plane length, parametric studies were done for performance comparison. According to this research, it is noticed that the antenna is tiny and new. It shows good performance in body case as well. Hence, the antenna is very suitable for healthcare applications.
\end{abstract}

Keywords: Band notch; compact size; ultra wide band antenna; novel antenna; on-body; body-centric communications; computer simulation technology (CST)

\section{Introduction}

Because of its unique properties, UWB technology has attracted both academics and industry in recent years. UWB communication has grown in popularity and innovation as a means of transmitting high-speed data across short distances. UWB technology allows for higher data rates and lower power emissions, as well as improved efficiency. Furthermore, constructing UWB networks needs less effort and difficulty, which has

This work is licensed under a Creative Commons Attribution 4.0 International License, which permits unrestricted use, distribution, and reproduction in any medium, provided the original work is properly cited. 
piqued the interest of many academics in this field; as a result, designing UWB antennas is growing increasingly famous by the day [1]. In healthcare applications for remote patient monitoring, UWB communication has a lot of potential in body-centric communications (BCWCs). The body-centric wireless network (BCWN), which is utilized in medical services to track patient' varied physical conditions, uses many sensors with multiple units spread all through human body to acquire important physiological data [2-3]. The measured physiological data captured and acquired by the sensors scattered across the human body will be sent to a human body worn access point. Antennas, on the other hand, are critical in BCWCs since they help to increase the efficiency of radio communications. The scope of BCWNs includes anything from chronic illness care for people and senior care to fundamental well-being monitoring and different sporting performance studies [2-4].

The Federal Communication Commission (FCC) announced in 2002 [5] that the frequency allotment for unregulated UWB data transmission has been increased from $3.1 \mathrm{GHz}$ to $10.6 \mathrm{GHz}$, which has sparked a lot of interest in the field. Because of UWB's high frequency range, antennas for this spectrum are tiny, which is ideal for wearable electronics [6-7].

There is a threat that interferes with the UWB system. That interference makes a device inefficient because of many narrow frequency bands such as $(5.2 \mathrm{GHz}$ and $5.7 \mathrm{GHz})$ of different wireless communication systems [8]. Therefore, avoiding interference with these frequencies in the UWB ranges is essential. To avoid interference, a band-notch feature is needed for the UWB antenna. Ultra-wideband and wearable technology needs compact size due to longer battery life and power-efficient communication without interference. The band notch is simply a band-rejection filter that allows many signal to pass unmodified while suppressing those in a particular range to minimal levels. As a result, a good antenna may be made to disregard the interference frequency. The primary goal of this research is to create a unique and small UWB notch wearable antenna for BCWC for e-health applications. The antenna will work in the UWB frequency ranges and reject unwanted narrow frequency bands. To develop energy-efficient connections among nodes scattered throughout the human body and also with off-body components, the antenna should be less sensitive to the existence of human lossy body tissues.

In [9-11], ultra-wideband wearable antennas for body-centric wireless communication have been presented. The antennas are compact and show good on-body performance. UWB on-body radio communications using different antennas have been investigated in [12-13]. Other particular frequency bands $(5.2 \mathrm{GHz}$ and $5.7 \mathrm{GHz})$ for various wireless communication systems generate interference in the UWB frequency spectrum. A band-notch technique is required to design interference-free, power-efficient communication. In [14-20], authors have presented UWB band notch antennas with different techniques for different frequency bands. They have also used the EBG technique for UWB band notch characteristics on the antenna structure. However, there is a minimal study of UWB band-notch antenna for wearable application in body-centric communications. In UWB on-body communications, wearable antennas need to be smaller in size and less interference to provide power-efficient communication. This paper proposes a very compact and novel band notch $(5.2 \mathrm{GHz}-5.8 \mathrm{GHz})$ antenna and designed using CST tool in the free space environment. The proposed antenna is novel because of the structure and band notch characteristics in the UWB frequency range. For UWB band notch wearable body centric communications, this novel shape antenna has not been proposed by any authors in the literature. In order to avoid interfering in the UWB resonance frequencies, the antenna configuration has a U-shaped slot. After investigating the antenna's free space performance for real-life realization, the antenna performance is evaluated on the human body modeled with a three-layer model. The antenna's operation in air as well as on the body was studied. However, the antenna is very less sensitive to the human body. The advantage of this antenna is that it has compact size, novel structure, band notch characteristics in the UWB frequency range. The antenna has excellent on-body performance, making it suited for UWB BCWCs with minimal interference. 
The rest of this paper is organized as follows: Section 2 of this work discusses UWB band notch proposed antenna. The antenna's simulated performance characteristics are presented in section 3 . The antenna was studied on a human body model in section 4 . Section 5 presents distance variation on body performance parameter study. Section 6 is dedicated to parametric study, and finally, in section 7 conclusion is discussed.

\section{UWB Band Notch Antenna Design}

Figures 1(a) and 1(b) depict the antenna's front and back orientations, respectively. The shape of the designed antenna looks like a 'swan' with a slotted patch. This antenna consists of three planer parts; the patch (radiating element), substrate, and the ground plane. The width and length of the substrate are the same. The suggested antenna's substrate is $25 \times 25 \mathrm{~mm}$ in overall dimension. Tab. 1 shows the summary of the dimensions of the proposed antenna. The wavelength of the antenna at the centre frequency of $6.85 \mathrm{GHz}$ is $43.80 \mathrm{~mm}$. The electrical size of the substrate is $\frac{\lambda}{1.75}$. The ground plane is made of annealed copper with a thickness of $0.035 \mathrm{~mm}$. It's secured to the base of the Roger RO4003C substrate layer (lossy). The substrate of the antenna has a relative permittivity of $\varepsilon=3.55$ and a loss tangent of 0.0027 . The ground part is rectangular, and it is partial at the rear side of the antenna. The ground plane measures 9 millimeters in length and 25 millimeters in width. The ground plane's length has an electrical size of $\frac{\lambda}{4.87}$. The antenna's radiating patch is linked to the substrate's top by a feed line. The width and length of the radiating material's electrical size are $\frac{\lambda}{1.75}$ and $\frac{\lambda}{3}$, respectively. A U-shape narrow slot is created on the feeding line to achieve band-notch characteristics in the UWB frequency range with proper impedance matching. Fig. 2 shows the dimension of the slot on the feed line. A waveguide port is attached to the excitation source. Fig. 3 depicts the antenna's waveguide port.

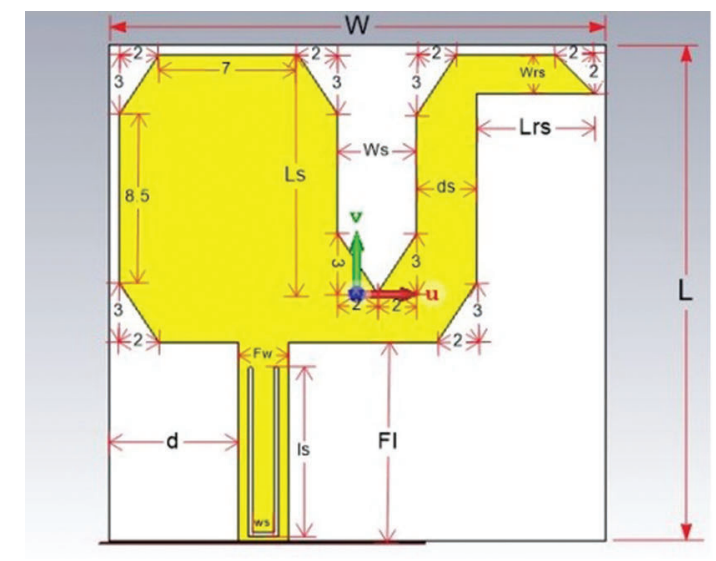

(a)

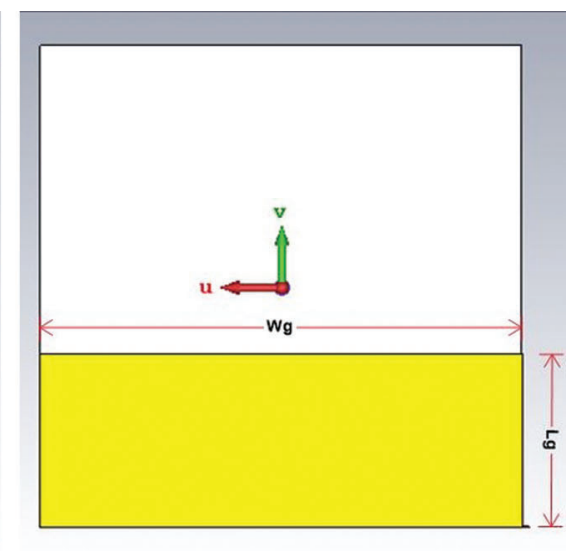

(b)

Figure 1: The designed UWB band notch antenna, from the (a) front and (b) back.

The feed line is $10 \mathrm{~mm}$ long and $2.5 \mathrm{~mm}$ wide. The feed-line Microstrip width is fixed at $2.5 \mathrm{~mm}$ for $50-\Omega$ impedance from $3.2 \mathrm{GHz}$ to $11 \mathrm{GHz}$. The thickness of the patch layer is $0.035 \mathrm{~mm}$. The substrate height is $1.139 \mathrm{~mm}$. The antenna's rectangle bottom layer is $9 \mathrm{~mm}$ long and $25 \mathrm{~mm}$ wide and is located 
on the underside. The antenna has a 0.035 millimeter thick radiating component. The gap, which provides adequate management between both the bottom edge patch and the ground plane, is used to specify the distance between both the rectangular patch and the ground plane printed on the back of the substrate for optimal bandwidth balancing. This CST software is very user-friendly and reliable. On the base of the antenna's feed line is a waveguide port with a length of $9.5 \mathrm{~mm}$ and a height of $8.1219 \mathrm{~mm}$.

Table 1: Summary of the dimensions of the antenna

\begin{tabular}{lll}
\hline SL No & Parameter & Dimensions (mm) \\
\hline 1 & Substrate Width, W & 25 \\
2 & Substrate Length, L & 25 \\
3 & Feedline Width, Fw & 2.5 \\
4 & Feedline Length, Fl & 10 \\
5 & Ls & 12 \\
6 & Ws & 4 \\
7 & Lrs & 6 \\
8 & Wrs & 2 \\
9 & Distance, ds & 4 \\
10 & Ground Plane Width. Wg & 25 \\
11 & Ground Plane Length. Lg & 9 \\
12 & Feed Gap & 1 \\
13 & Position of Feed Point, d & 6.5 \\
\hline
\end{tabular}

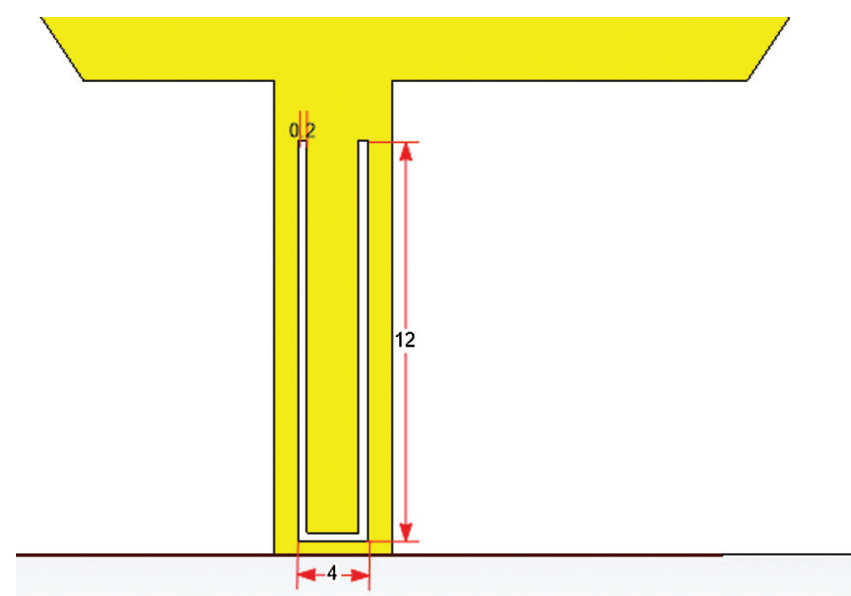

Figure 2: Dimension of slot on the feed line

\section{Free Space Performance of UWB Band Notch Antenna}

For free space simulation, different performance parameters of the designed antenna were done by Computer Simulation Technology Microwave Studio electromagnetic simulator (CST MWS) tool. 


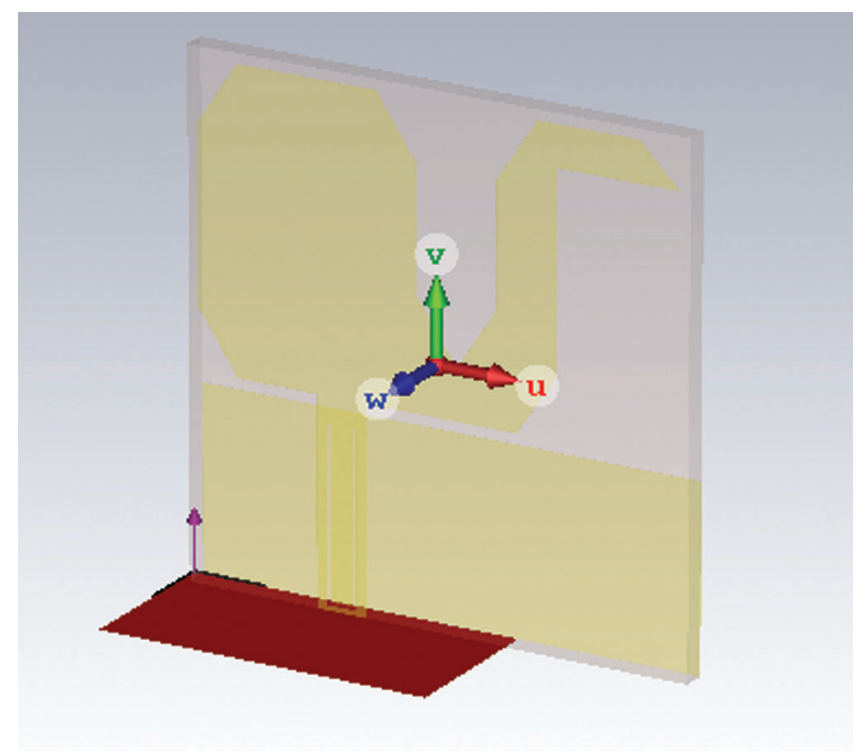

Figure 3: Waveguide port of the proposed antenna

\subsection{Return Loss Result}

Return loss is one of the prime parameters to measure antenna performance. The antenna's free space return loss curve is shown in Fig. 4 below. The antenna has quite a good bandwidth of $3.2 \mathrm{GHz}$ to $11 \mathrm{GHz}$ and a return loss curve of less than $-10 \mathrm{~dB}$, which includes a spectrum notch that covers the region of $4.5 \mathrm{GHz}$ to $6.1 \mathrm{GHz}$ and efficiently avoids interference with existing WLAN and WiMAX systems. This band-notch characteristic makes this novel antenna suitable for power-efficient and interference-less communication in wireless wearable body sensors networks.

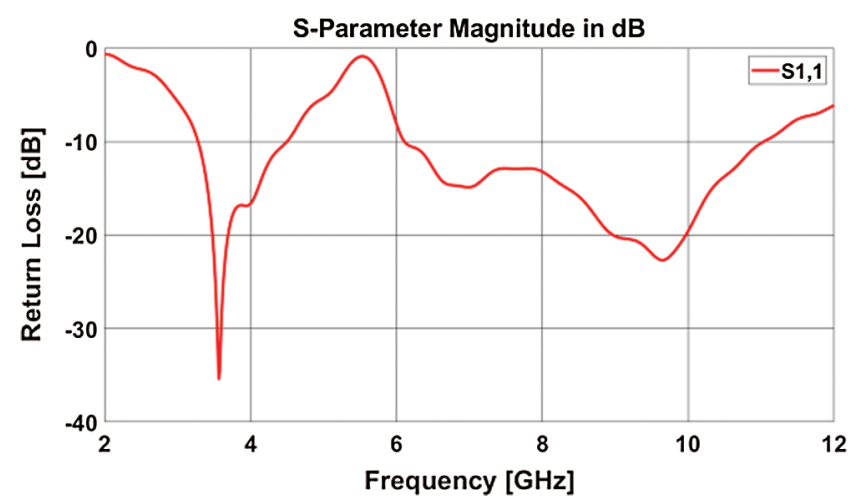

Figure 4: The antenna's return loss curve.

\subsection{Gain, Radiation Efficiency and Radiation Pattern}

Antenna gain, radiation efficiency, and radiation pattern are simulated for $3.5 \mathrm{GHz}, 5.2 \mathrm{GHz}, 5.8 \mathrm{GHz}$, $8 \mathrm{GHz}$, and $10 \mathrm{GHz}$. A maximum gain of $3.454 \mathrm{dBi}$ is achieved at frequency $10 \mathrm{GHz}$ during the free space simulation. $95.97 \%$ of radiation efficiency is found at frequency $3.5 \mathrm{GHz}$. Tab. 2 shows free space gain and radiation efficiency for different frequencies. The three-dimensional (3D), E, and $\mathrm{H}$ plane radiation patterns are shown in Figs. 5, 6, 7, 8, and 9. At $5.8 \mathrm{GHz}$, due to band notch, the lowest radiation efficiency of $69.76 \%$ 
is noticed, and that is expectable. The radiation patterns of this antenna at most of the frequencies look nearly omnidirectional. However, at $10 \mathrm{GHz}$, the radiation looks a bit distorted. Previous studies have noted that for UWB antenna cases, the radiation pattern at higher frequencies shows distorted behavior.

Table 2: Free space gain and radiation efficiency

\begin{tabular}{llllll}
\hline Frequency $(\mathrm{GHz})$ & 3.5 & 5.2 & 5.8 & 8 & 10 \\
\hline Free Space Gain (dBi) & 2.68 & 2.85 & 2.11 & 1.99 & 3.45 \\
Free Space Radiation Efficiency (\%) & 95.97 & 91.8 & 69.76 & 83.86 & 84.30 \\
\hline
\end{tabular}

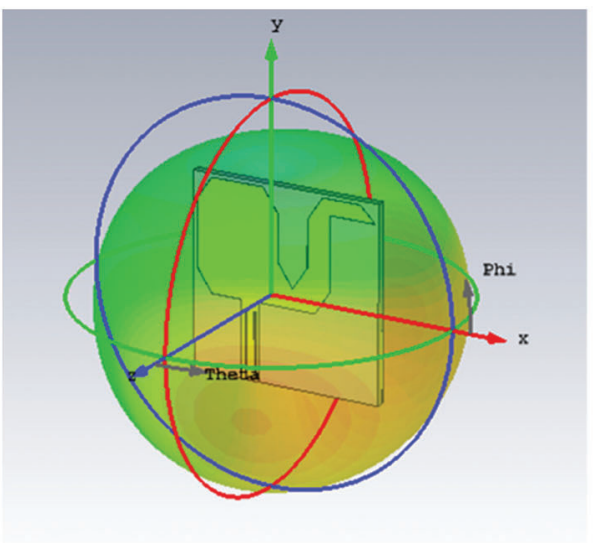

(a) 3-D radiation at $3.5 \mathrm{GHz}$

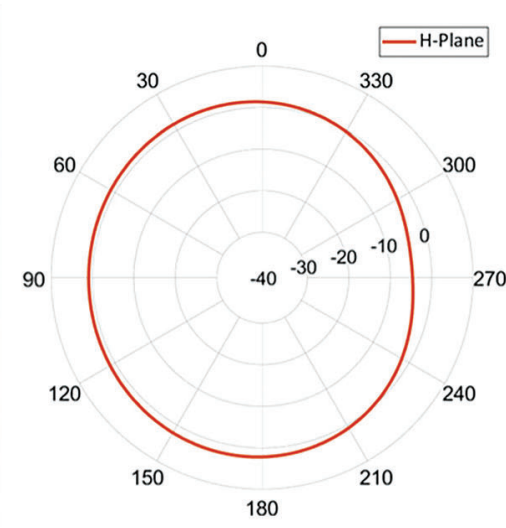

(b) H-Plane

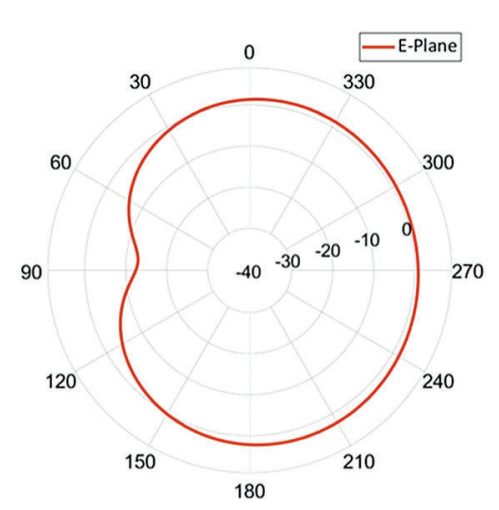

(c) E-plane

Figure 5: Free space radiation pattern at 3.5 GHz. (a) 3-D Pattern (b) H-Plane (c) E-Plane

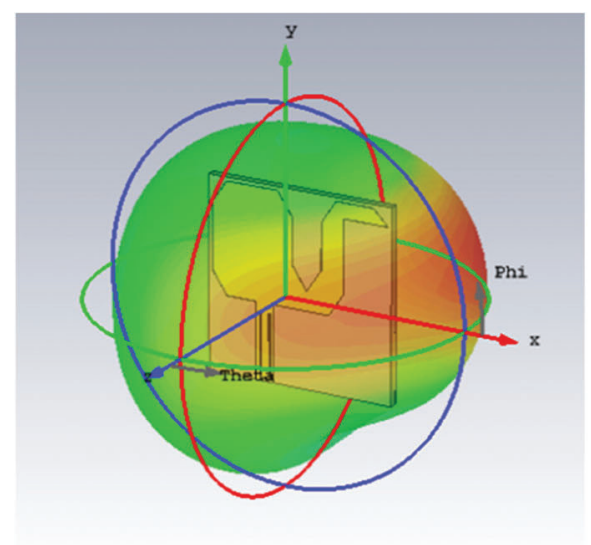

(a)

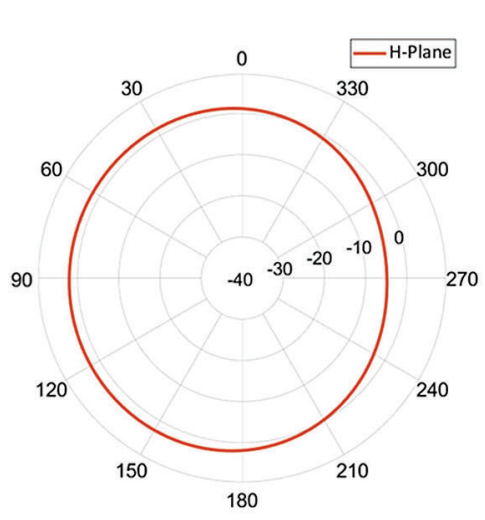

(b)

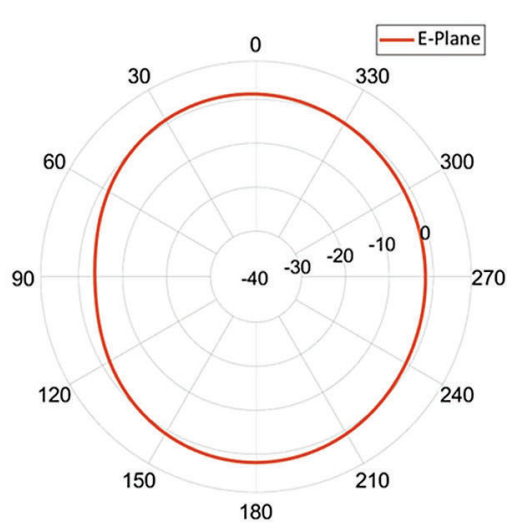

(c)

Figure 6: Free space radiation pattern at $5.2 \mathrm{GHz}$. (a) 3-D pattern, (b) H-plane and (c) E-plane 


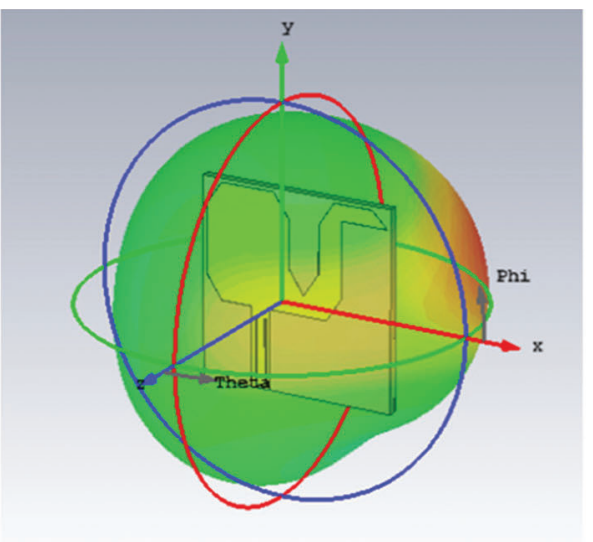

(a)

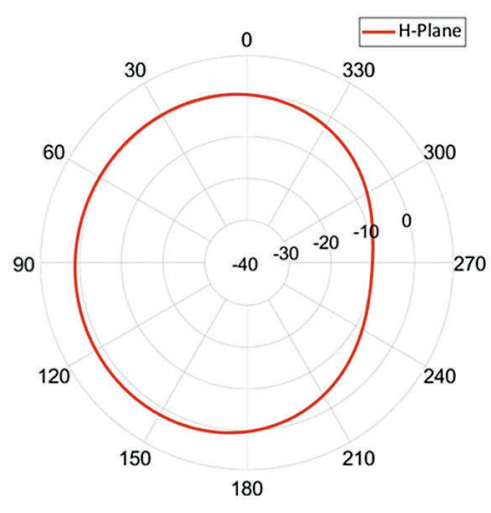

(b)

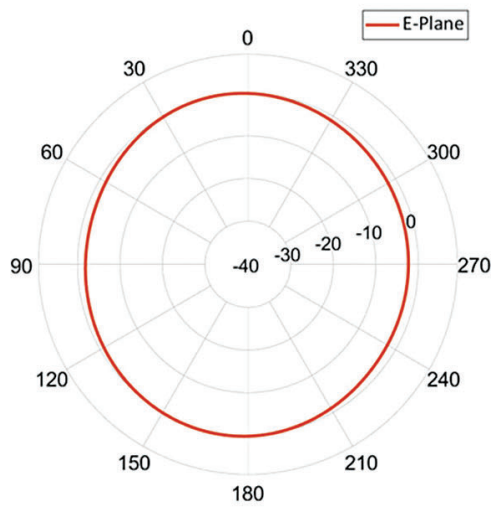

(c)

Figure 7: Free space radiation pattern at 5.8 GHz. (a) 3-D Pattern (b) H-Plane (c) E-Plane

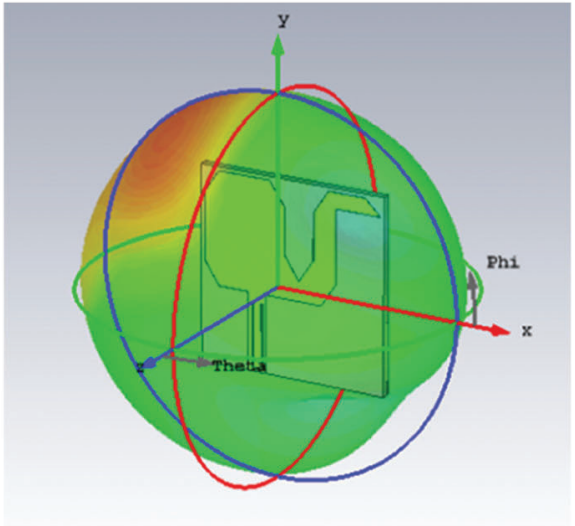

(a)

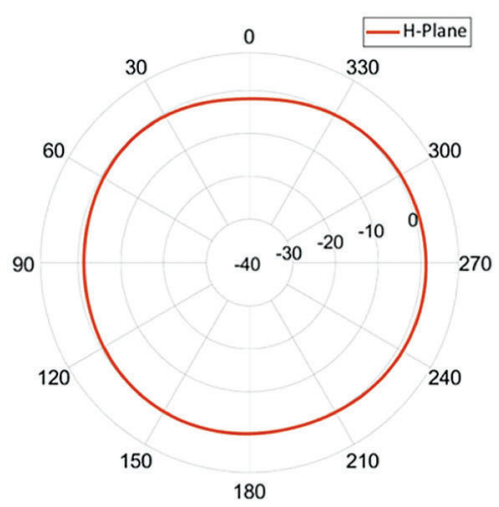

(b)

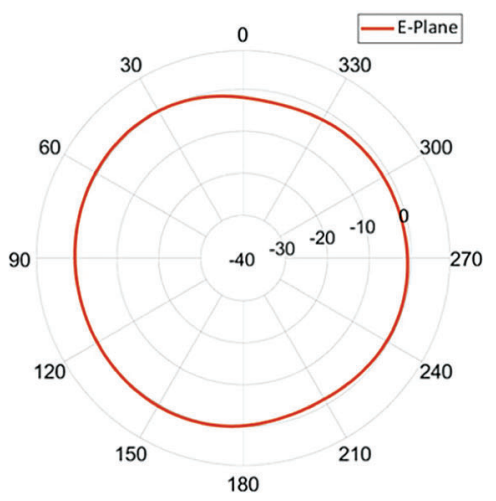

(c)

Figure 8: Free space radiation pattern at $8 \mathrm{GHz}$. (a) 3-D Pattern (b) H-Plane (c) E-Plane

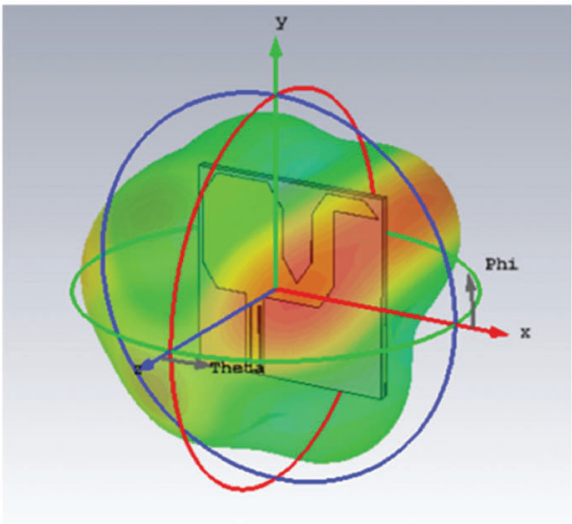

(a)

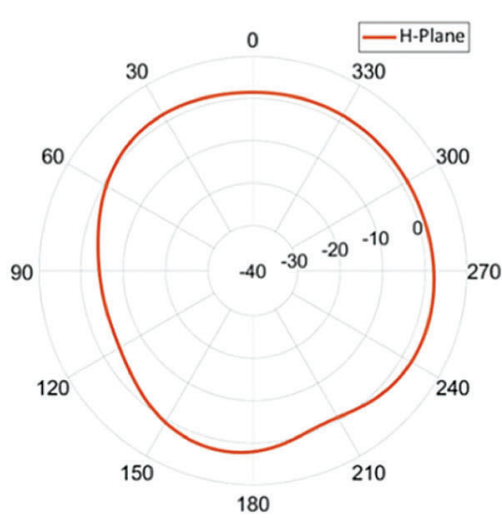

(b)

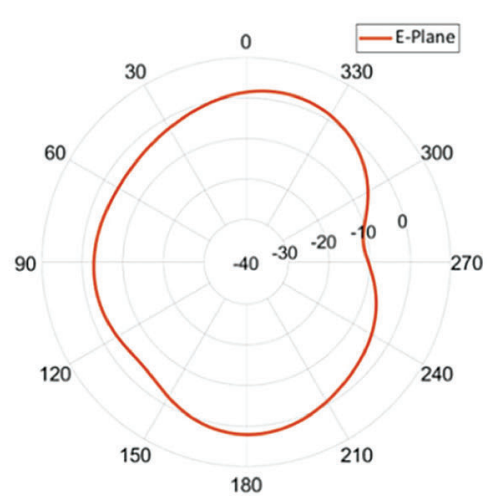

(c)

Figure 9: Free space radiation pattern at 8 GHz. (a) 3-D Pattern (b) H-Plane (c) E-Plane 


\section{On-Body Performance}

The antenna was mounted on the torso phantom body model for on-body simulation to study the effect of the phantom body on antenna parameters, as illustrated in Fig. 10. The selected phantom body design in this work comprises of the 3 outermost layers of a human body (skin, fat, and muscle). The average depth of adult human skin is about $2 \mathrm{~mm}$, fat is about $4 \mathrm{~mm}$, and muscle depth is about $20 \mathrm{~mm}$. Tab. 3 shows the dimension of three different human tissues (skin, fat, and muscle). Fig. 10 depicts the antenna arrangement as well as a three-layer human body structure.

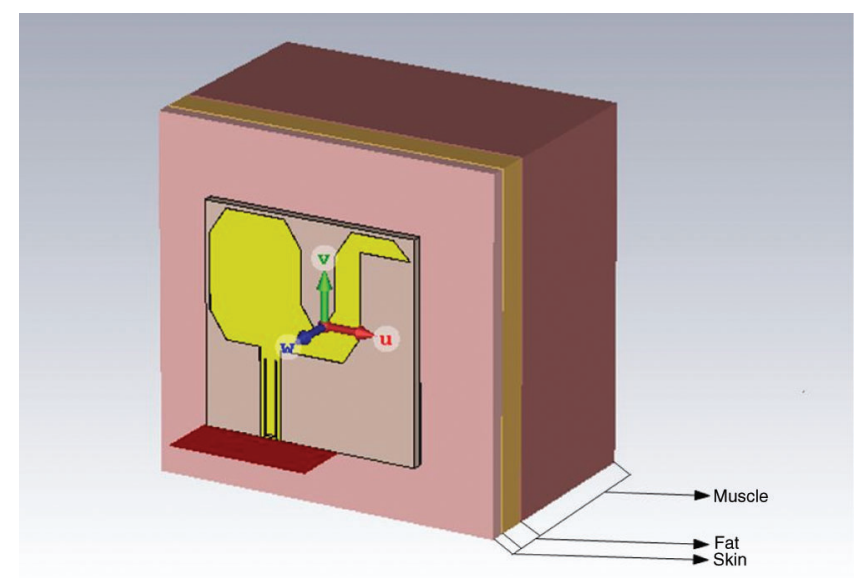

Figure 10: Proposed Antenna with Phantom Body Model (Skin, Fat, and Muscle)

Table 3: Dimension of three different human tissues (skin, fat, and muscle)

\begin{tabular}{llll}
\hline Phantom Tissues & Thickness $(\mathrm{mm})$ & Length $(\mathrm{mm})$ & Width $(\mathrm{mm})$ \\
\hline Skin & 2 & 40 & 40 \\
Fat & 4 & 40 & 40 \\
Muscle & 20 & 40 & 40 \\
\hline
\end{tabular}

During simulations, a $4 \mathrm{~mm}$ gap was realized between both the antenna and the first layer (skin) of the phantom model. The dielectric characteristics of the human body fluctuate with frequency, resulting in dispersed tissue demonstration [21]. The relative permittivity and electric conductivity of all the layers of the human body model where skin, fat and muscle formation is determined during the CST simulations. Tab. 4 shows the values of dielectric properties (relative permittivity) of different tissues like skin, fat, and muscle for various frequencies $3.5 \mathrm{GHz}, 5.2 \mathrm{GHz}, 5.8 \mathrm{GHz}, 8 \mathrm{GHz}$, and $10 \mathrm{GHz}$.

\subsection{Comparison of Return Loss}

In comparison to free space, the return loss has shifted a bit after positioning the antenna just above phantom body model. Figure 11 illustrates a comparison of the return loss curves in free space and at a distance of $4 \mathrm{~mm}$ from the body model. The whole on-body return loss graph was somewhat left-shifted, but the notched frequency band remained within the intended range, as seen in Fig. 11. 
Table 4: Dielectric properties skin, fat and muscle

\begin{tabular}{llll}
\hline Frequency $(\mathrm{GHz})$ & \multicolumn{3}{c}{ Relative Permittivity } \\
\cline { 2 - 4 } & Skin & Fat & Muscle \\
\hline $3.5 \mathrm{GHz}$ & 37.00 & 5.18 & 51.44 \\
$5.2 \mathrm{GHz}$ & 35.61 & 5.01 & 49.27 \\
$5.8 \mathrm{GHz}$ & 35.11 & 4.95 & 48.78 \\
$8 \mathrm{GHz}$ & 33.18 & 4.76 & 45.49 \\
$10 \mathrm{GHz}$ & 31.29 & 4.60 & 42.76 \\
\hline
\end{tabular}

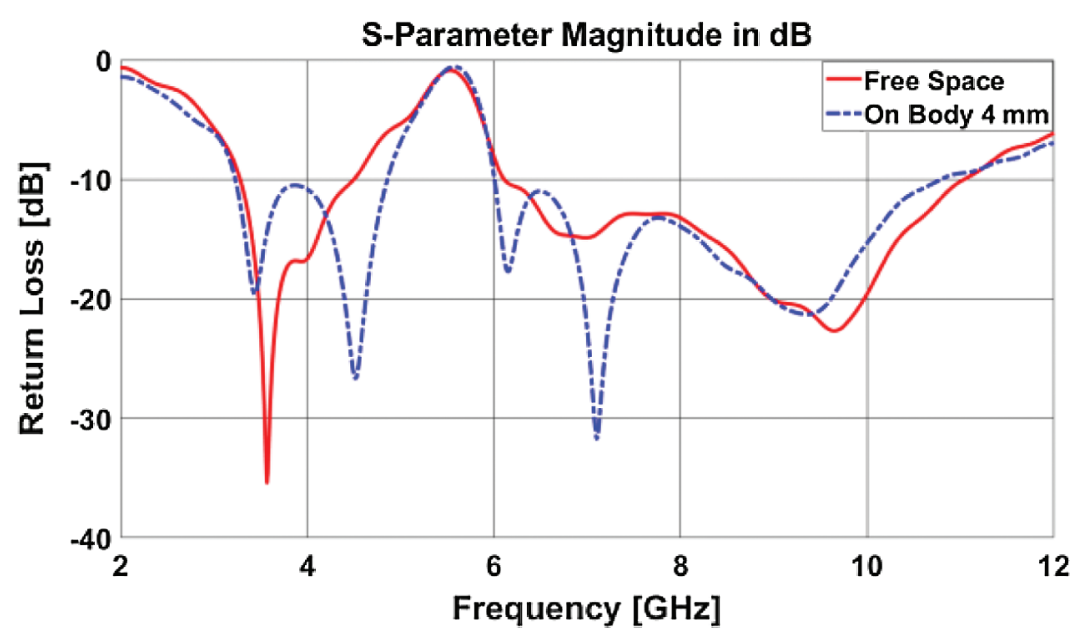

Figure 11: Comparison of return loss curve between the free space and $4 \mathrm{~mm}$ distance away from on body responses of the proposed antenna

\subsection{Antenna Gain Comparison}

Antenna gain at both $4 \mathrm{~mm}$ distance away from on-body and free space is simulated and compared at different frequencies. Tab. 5 listed the comparison of gain of proposed antenna. From the table, it is seen that at $3.5 \mathrm{GHz}$, the antenna gain is very poor at a $4 \mathrm{~mm}$ distance away. For other frequencies, the antenna gain is good enough for wearable applications with good power transmission. Except for the band-notch region, the antenna performance is quite good, and in the band-notch region, it is inactive and desirable and expected. This is the objective of band-notch features in the UWB antenna design.

Table 5: Comparison of antenna gain of proposed antenna in free space and $4 \mathrm{~mm}$ distance away from phantom at different frequencies

\begin{tabular}{llllll}
\hline Frequency $(\mathrm{GHz})$ & 3.5 & 5.2 & 5.8 & 8 & 10 \\
\hline Free Space Gain $(\mathrm{dBi})$ & 2.68 & 2.85 & 2.11 & 1.99 & 3.45 \\
Gain $(\mathrm{dBi})$ 4 mm away from the human body model & -5.46 & 1.18 & 1.38 & 5.9 & 8.08 \\
\hline
\end{tabular}




\subsection{Antenna Radiation Pattern Comparison}

The designed antenna's radiation patterns are first examined in free space simulation and then on a phantom model that is $4 \mathrm{~mm}$ away from the antenna. All the radiation patterns are monitored in both azimuth and elevation planes. Azimuth is the top-down view of the radiation pattern which is spread out horizontally (H-plane for horizontal) Elevation is the side view of the antenna and its vertical radiation pattern (E-plane is for elevation). The radiation patterns of free space and on-body were shown in Figs. 12, 13, 14, 15, and 16 when the antenna was positioned $4 \mathrm{~mm}$ away from the phantom of the proposed antenna. The free space radiation patterns of these different frequencies present mostly omnidirectional patterns. In contrast, on-body radiation patterns show slightly irregular on both planes as phantom body tissues act as a lossy medium that absorbs radiation. Figs. 12 to 16 blue color shows the free space radiation patterns, and the red color represents the on-body radiation patterns for both $\mathrm{E}$ and $\mathrm{H}$ planes.

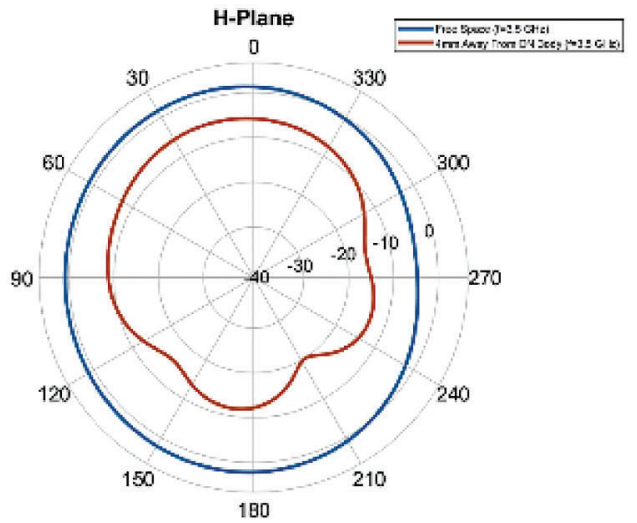

(a)

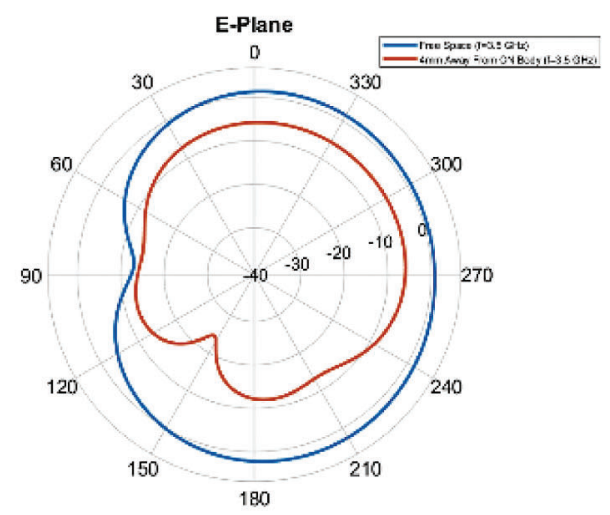

(b)

Figure 12: At $3.5 \mathrm{GHz}$, a comparison of radiation patterns: (a) On H-Plane and (b) On E-Plane

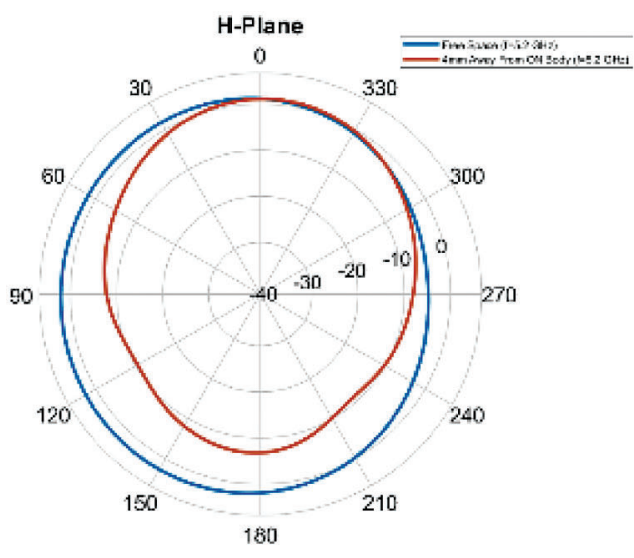

(a)

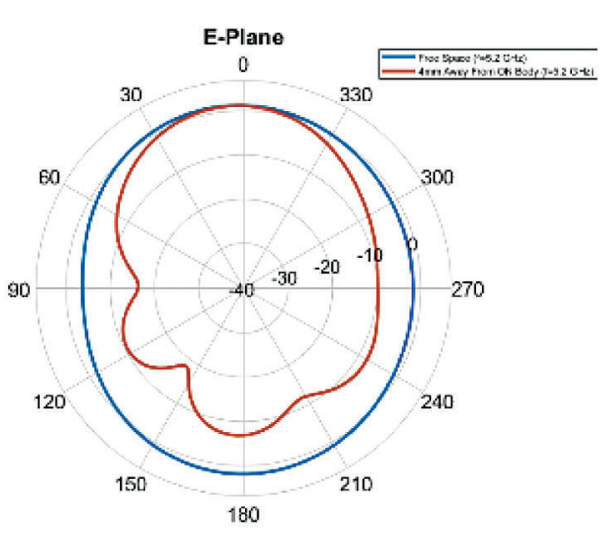

(b)

Figure 13: At $5.2 \mathrm{GHz}$, a comparison of radiation patterns: (a) On H-Plane; (b) On E-Plane 


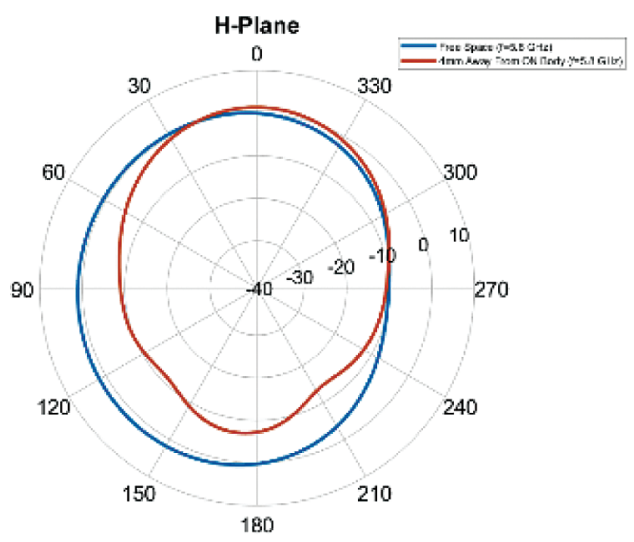

(a)

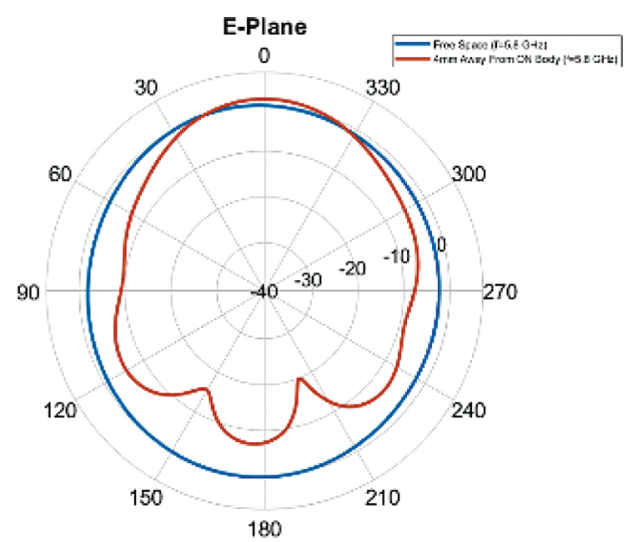

(b)

Figure 14: At $5.8 \mathrm{GHz}$, a comparison of radiation patterns: (a) On H-Plane; (b) On E-Plane

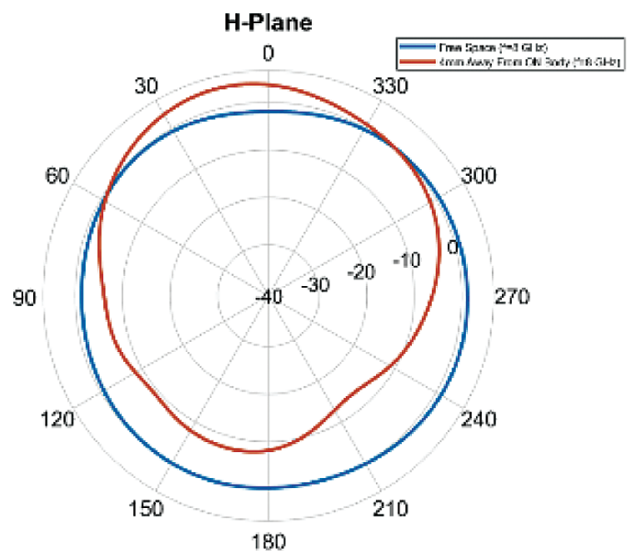

(a)

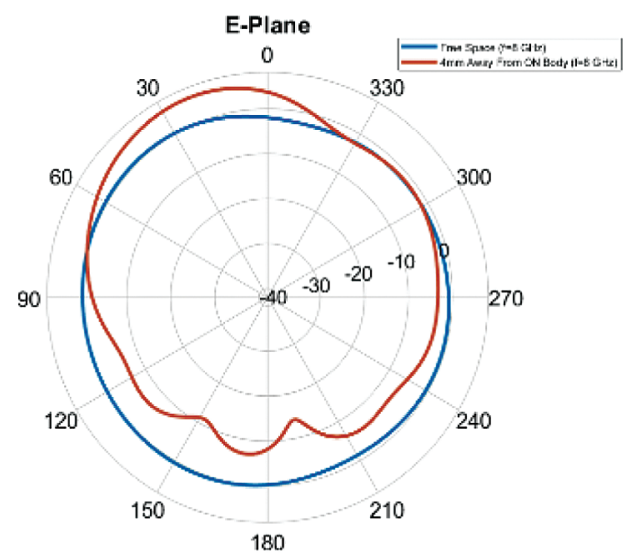

(b)

Figure 15: At $8 \mathrm{GHz}$, a comparison of radiation patterns: (a) On H-Plane; (b) On E-Plane

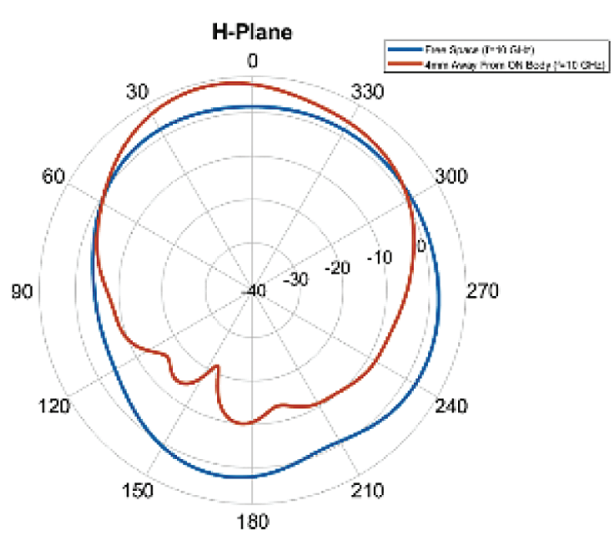

(a)

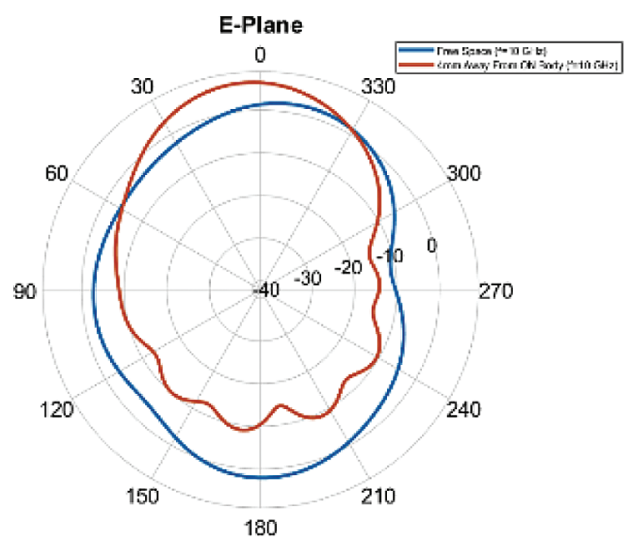

(b)

Figure 16: At $10 \mathrm{GHz}$, a comparison of radiation patterns: (a) On H-Plane; (b) On E-Plane 


\subsection{Radiation Efficiency Comparison}

Antenna radiation efficiency on both $4 \mathrm{~mm}$ distance away from on-body and free space are simulated and compared at various frequencies. Tab. 6 listed the comparison of radiation efficiency of the antenna. Although the radiation efficiency on the body decreases, it remains within acceptable ranges. As the phantom body act as a lossy medium, the power absorbed by the phantom body tissues results in low radiation efficiency than free space. At $5.8 \mathrm{GHz}$, the antenna efficiency is poor, $69.76 \%$ at free space and $25.67 \%$ at on body. This indicates the effectiveness of band-notch characteristics. At $10 \mathrm{GHz}$, the antenna efficiency is high, $84.29 \%$ in free space and $61.07 \%$ at on-body. The on-body simulation studies are quite steady and comparable to free space at higher frequencies.

Table 6: Comparison of radiation efficiency of the antenna

\begin{tabular}{llllll}
\hline Frequency (GHz) & 3.5 & 5.2 & 5.8 & 8 & 10 \\
\hline Free Space Radiation Efficiency (\%) & 95.97 & 91.8 & 69.76 & 83.86 & 84.30 \\
On-body 4 mm away from human phantom radiation efficiency $(\%)$ & 11.2 & 24.67 & 25.67 & 57.99 & 61.07 \\
\hline
\end{tabular}

\section{Distance Variation on Body Performance Parameter Study}

To investigate the distance variation of on-body antenna performance, the antenna is simulated placing on a phantom body model consisting of skin, fat, and muscle layers.

\subsection{Return Loss Comparison for Different Distances from the Body}

The antenna was positioned at various distances from the phantom body model during on-body simulation. The designed antenna's return loss curves for various gaps are shown in Fig. 17. When the antenna was replicated by positioning it at various distances from the phantom body model, the return loss curve changed slightly to the left. As the separation between the phantom body and the antenna grows, the performance improves. After the simulation in all distance cases, the band notch characteristics of the antenna remain the same, and they showed band notch behavior. Fig. 17 shows that improved return loss response occurs at distances of $4 \mathrm{~mm}, 6 \mathrm{~mm}, 8 \mathrm{~mm}$, and $10 \mathrm{~mm}$ from the phantom body model. At $8 \mathrm{~mm}$ and $10 \mathrm{~mm}$ gaps, good impedance matching performance may be found.

\subsection{Antenna Gain and Radiation Efficiency Comparison for Different Distances from the Body}

Tab. 7 shows the comparison of antenna gain and radiation efficiency of the proposed antenna.

From Tab. 7, it is observed that the antenna shows better value when the gap between the proposed antenna and the phantom body model raises. Very poor gain is seen at the $3.5 \mathrm{GHz}$ due to no transmission. Nevertheless, at $4 \mathrm{~mm}, 6 \mathrm{~mm}, 8 \mathrm{~mm}$, and $10 \mathrm{~mm}$ distances, this antenna presents a better result. Because of the reflections and refraction involved in the phantom body model, the antenna's radiation pattern alters when it is put on it. As a result, the antenna's gain grows as the separation between it and the phantom body grows. For example, at $10 \mathrm{GHz}$, the designed antenna attained a good on-body gain of $8.089 \mathrm{dBi}$ when kept at a $4 \mathrm{~mm}$ distance.

When the antenna is put on the phantom body, it absorbs power since it behaves as a lossy medium. As a result, during the on-body scenario, the radiation efficiency drops. The radiation efficiency of an on-body antenna improves as the separation grows. When the proposed antenna is placed $10 \mathrm{~mm}$ away from the 
phantom body model, it shows very good on-body radiation efficiency of $41.17 \%, 58.88 \%, 57.13 \%, 74.58 \%$, and $72.52 \%$ for $3.5 \mathrm{GHz}, 5.2 \mathrm{GHz}, 5.8 \mathrm{GHz}, 8 \mathrm{GHz}$, and $10 \mathrm{GHz}$ respectively.

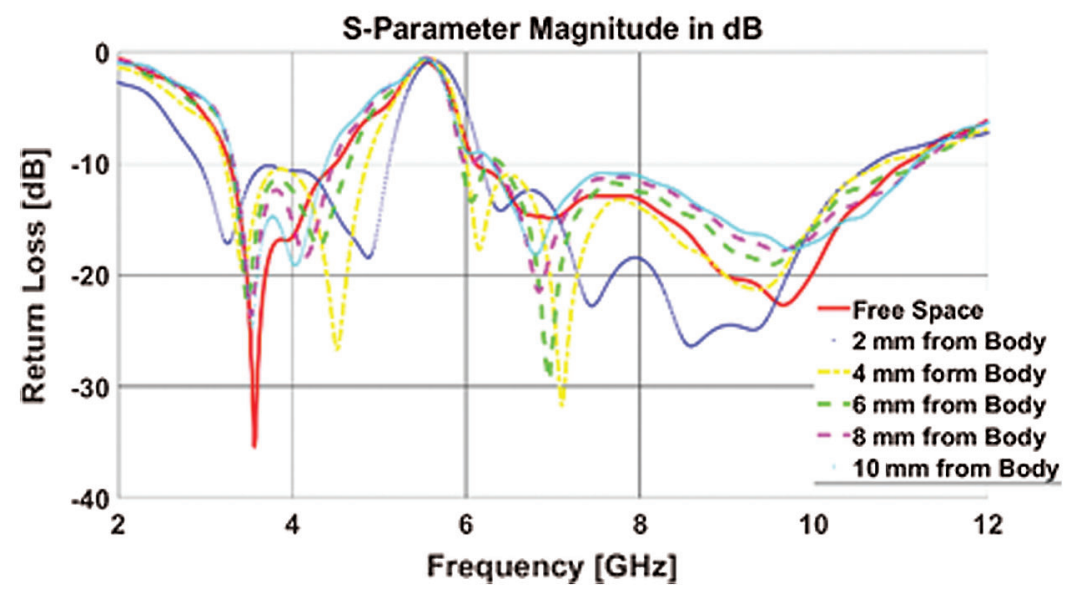

Figure 17: S-Parameter (return loss curves) comparison at different distances of antenna away from the body model, including free space return loss

Table 7: Comparison of radiation efficiency and gain for various gaps

\begin{tabular}{llllll}
\hline Antenna Parameters & $3.5 \mathrm{GHz}$ & $5.2 \mathrm{GHz}$ & $5.8 \mathrm{GHz}$ & $8 \mathrm{GHz}$ & $10 \mathrm{GHz}$ \\
\hline $\begin{array}{l}\text { Radiation Efficiency (\%) } \\
\text { Free Space }\end{array}$ & 95.97 & 91.8 & 69.76 & 83.86 & 84.29 \\
$\begin{array}{l}\text { Radiation Efficiency (\%) } \\
2 \text { mm away from body }\end{array}$ & 6.98 & 8.20 & 11.43 & 38.5 & 43.8 \\
$\begin{array}{l}\text { Radiation Efficiency (\%) } \\
4 \text { mm away from body }\end{array}$ & 11.2 & 24.67 & 25.67 & 57.99 & 61.07 \\
$\begin{array}{l}\text { Radiation Efficiency (\%) } \\
6 \text { mm away from body }\end{array}$ & 19.11 & 39.38 & 38.36 & 66.74 & 67.35 \\
$\begin{array}{l}\text { Radiation Efficiency (\%) } \\
8 \text { mm away from body }\end{array}$ & 30.54 & 50.15 & 50.26 & 71.37 & 70.85 \\
$\begin{array}{l}\text { Radiation Efficiency (\%) } \\
10 \text { mm away from body }\end{array}$ & 41.17 & 58.88 & 57.13 & 74.58 & 72.52 \\
$\begin{array}{l}\text { Gain (dBi) } \\
\text { Free Space }\end{array}$ & 2.68 & 2.85 & 2.11 & 1.99 & 3.5 \\
$\begin{array}{l}\text { Gain (dBi) } \\
2 \text { mm away from body }\end{array}$ & -6.68 & -4.17 & -4.57 & 4.44 & 7.03 \\
$\begin{array}{l}\text { Gain (dBi) } \\
4 \text { mm away from body }\end{array}$ & -5.45 & 1.18 & 1.38 & 5.9 & 8.08 \\
$\begin{array}{l}\text { Gain (dBi) } \\
6 \text { mm away from body }\end{array}$ & -2.61 & 3.54 & 3.71 & 5.72 & 7.86 \\
\hline
\end{tabular}


Table 7 (continued).

\begin{tabular}{llllll}
\hline Antenna Parameters & $3.5 \mathrm{GHz}$ & $5.2 \mathrm{GHz}$ & $5.8 \mathrm{GHz}$ & $8 \mathrm{GHz}$ & $10 \mathrm{GHz}$ \\
\hline $\begin{array}{l}\text { Gain (dBi) } \\
8 \text { mm away from body }\end{array}$ & -0.33 & 4.71 & 4.92 & 5.37 & 7.24 \\
$\begin{array}{l}\text { Gain (dBi) } \\
10 \text { mm away from body }\end{array}$ & 1.13 & 5.35 & 5.33 & 4.96 & 6.41 \\
\hline
\end{tabular}

\section{Parametric Study}

The impact of changing key factors like slot size and spacing on antenna performance were investigated in this study. The length of the slots was modified from $18.08 \mathrm{~mm}$ to $16.57 \mathrm{~mm}$ and $19.89 \mathrm{~mm}$, respectively. The size of the ground plane was modified from $9 \mathrm{~mm}$ to $8.5 \mathrm{~mm}$ and $9.5 \mathrm{~mm}$.

\subsection{Variation of Slot Length}

The Shawn-shaped antenna patch, substrate, and ground plane were preserved to the same dimensions as the previous section for slot lengths of $16.57 \mathrm{~mm}$ and $19.89 \mathrm{~mm}$. Thus, only slot length was changed from $18.08 \mathrm{~mm}$ to $16.57 \mathrm{~mm}$ and $19.89 \mathrm{~mm}$. Fig. 18 shows that the return loss curve's band notch portion shifted to the left for slot length $19.89 \mathrm{~mm}$ and band notch portion shifted to the right for slot length $16.57 \mathrm{~mm}$. The radiation efficiency was $94.41 \%$ (highest) at $3.5 \mathrm{GHz}$ for $16.57 \mathrm{~mm}$ slot length and $94.57 \%$ (highest) $3.5 \mathrm{GHz}$ for $19.89 \mathrm{~mm}$ slot length. The maximum gain achieved was $3.801 \mathrm{~dB}$ and $3.242 \mathrm{~dB}$ at $10 \mathrm{GHz}$ for $16.57 \mathrm{~mm}$ and $19.89 \mathrm{~mm}$ slot length, respectively.

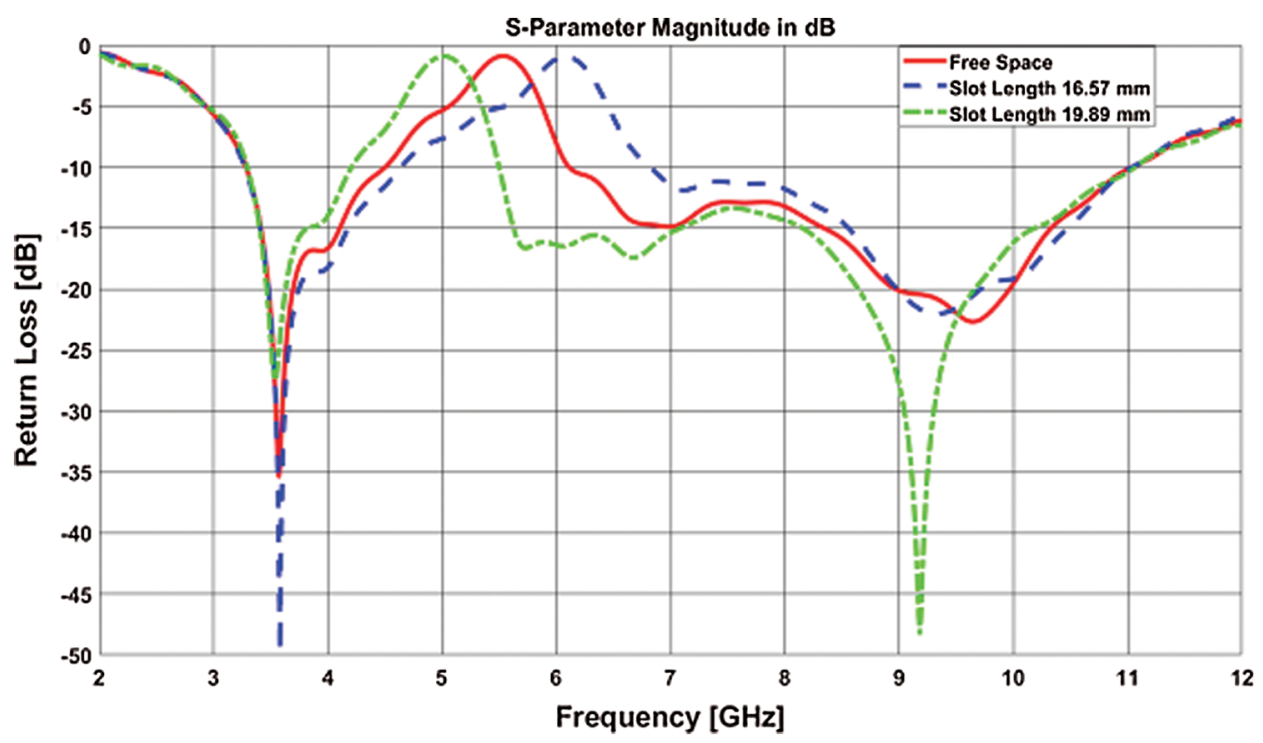

Figure 18: Return loss curve for different slot length

\subsection{Variation of Ground Plane Length}

The main antenna was maintained $9 \mathrm{~mm}$ ground plane length. A change of ground plane length to $8.5 \mathrm{~mm}$ causes the return loss curve to slightly left shift, and ground plane length $9.5 \mathrm{~mm}$ causes the return loss curve to a little bit right shift. Although, the notched frequency band remains within the 
desired range. Fig. 19 presents the return loss curve for the ground plane's different lengths. The maximum gain of $3.115 \mathrm{~dB}$ and $3.773 \mathrm{~dB}$ was achieved at $10 \mathrm{GHz}$ for $8.5 \mathrm{~mm}$ and $9.5 \mathrm{~mm}$ ground plane length. The maximum radiation efficiency was $93.70 \%$ for $9.5 \mathrm{~mm}$ ground plane length and $96.05 \%$ for $8.5 \mathrm{~mm}$ ground plane length.

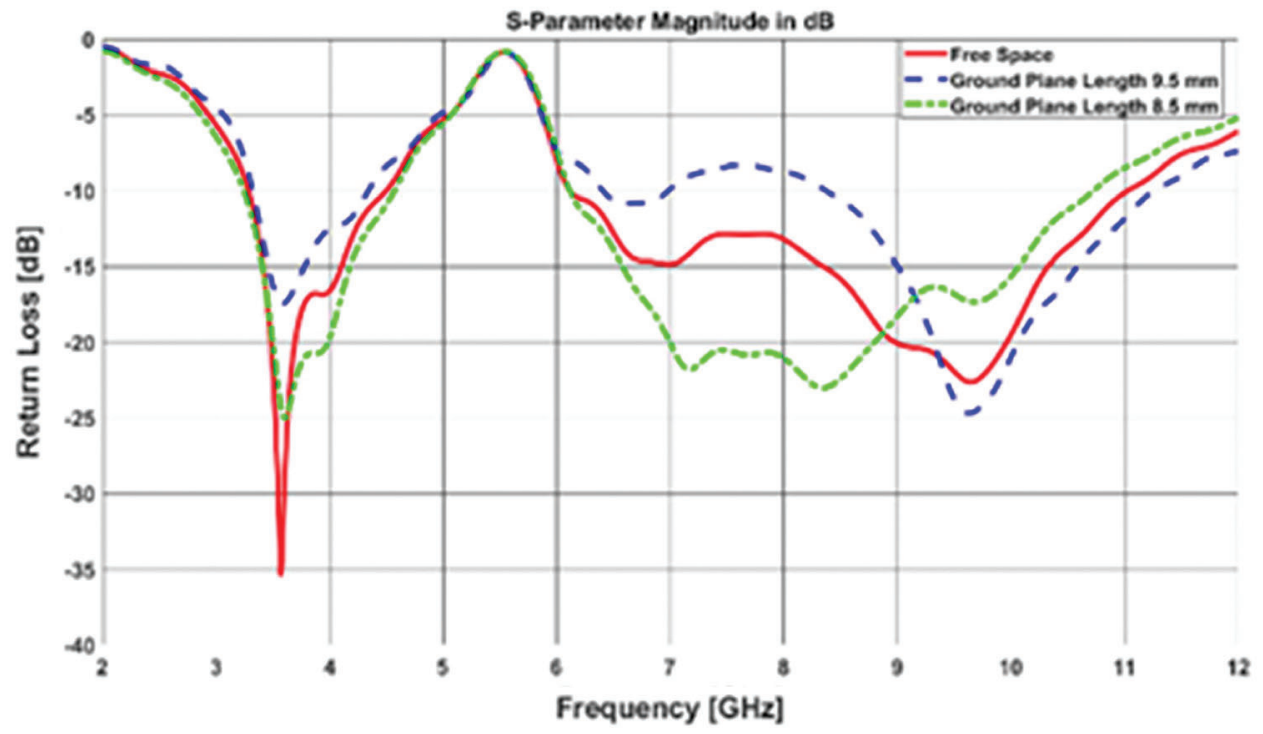

Figure 19: Return loss curves for different ground plane length

\section{Conclusion}

The major goal of this work is to build a new tiny UWB antenna for body-centric communication with band notched features. At different frequencies, the performance parameters of this UWB antenna were investigated in free space and on a 3-layer phantom body model at a close distance. The intended antenna is very compact in size and it has the ability to avoid the interference caused by some other existing network systems. The on-body results of the antenna are at an acceptable level for BCWCs. The results of the on-body antenna performance parameters and analysis revealed that the proposed antenna could be placed $4 \mathrm{~mm}$ away from the body to achieve the best results for power-efficient and inference-free communication. From on-body performance parameters, the proposed UWB band-notch antenna is less sensitive due to the effects of the phantom body model. So it can be said that due to its tiny size, novel shape, and significant on-body performance, the proposed antenna can serve practical working fields like medical applications and sports applications. Due to lack of scope, this study is based on simulation results. CST software provides very close results to measurement as found in the literature.

Acknowledgement: We would like to give special thanks to Taif University Researchers supporting project number (TURSP-2020/216), Taif University, Taif, Saudi Arabia.

Funding Statement: Taif University Researchers are supporting project number (TURSP-2020/216), Taif University, Taif, Saudi Arabia.

Conflicts of Interest: The authors declare that they have no conflicts of interest to report regarding the present study. 


\section{References}

[1] H. G. Schantz, "Introduction to ultra-wideband antennas," in Proc. IEEE Conference on Ultra Wideband Systems and Technologies, Reston, VA, USA, pp. 1-9, 2003.

[2] P. S. Hall and Y. Hao, Antennas and Propagation for Body-Centric Wireless Communications, 2nd ed. Norwood, Mass, USA: Artech House, 2006.

[3] J. Foerester, E. Green, S. Somayazulu and D. Leeper, "Ultrawideband for short- or medium-range wireless communications," Intel Technology Journal, vol. Q2, pp. 1-11, 2001.

[4] M. Presser, T. Brown, A. Goulianos, S. Stavrou and R. Tafazolli, "Body centric context aware application scenarios," in Proc. IET Seminar on Antennas and Propagation for Body-Centric Wireless Communications, London, UK, pp. 19-23, 2007.

[5] A. Alomainy, A. Sani, A. Rahman, J. G. Santas and Y. Hao, "Transient characteristics of wearable antennas and radio propagation channels for ultrawideband body-centric wireless communications," IEEE Transactions on Antennas and Propagation, vol. 57, no. 4, pp. 875-884, 2009.

[6] M. Klemm, I. Z. Kovcs, G. F. Pedersen and G. Troster, "Novel small-size directional antenna for UWB WBAN/WPAN applications," IEEE Transactions on Antennas and Propagation, vol. 53, no. 12, pp. 38843896, 2005.

[7] N. Chahat, M. Zhadobov, R. Sauleau and K. Ito, "A compact UWB antenna for on-body applications," IEEE Transactions on Antennas and Propagation, vol. 59, no. 4, pp. 1123-1131, 2011.

[8] H. Liu, C. Ku, T. Wang and C. Yang, "Compact monopole antenna with band-notched characteristic for UWB applications," IEEE Antennas and Wireless Propagation Letters, vol. 9, pp. 397-400, 2010.

[9] B. Yeboah-Akowuah, P. Kosmas and Y. Chen, "A Q-slot monopole for UWB body-centric wireless communications," IEEE Transactions on Antennas and Propagation, vol. 65, no. 10, pp. 5069-5075, 2017.

[10] M. M. Khan, I. Mobin, G. Palikaras and E. Kallos, "Study of a small printed quasi-self-complementary ultra wideband antenna for on-body applications," in Proc. 4th Computer Science and Electronic Engineering Conference (CEEC), Colchester, UK, pp. 179-183, 2012.

[11] M. M. Khan, A. K. M. M. Alam, M. A. Talha and P. Kumar, "Investigation of a compact ultra wideband antenna for wearable applications," International Journal on Communications Antenna and Propagation, vol. 4, no. 4, pp. 124-129, 2014.

[12] M. M. Khan, M. A. Rahman, A. Alomainy and C. Parini, "On-body radio channel performance of a small printed quasi-self-complementary ultra wideband antenna," in Proc. 2nd Int. Conf. on Advances in Electrical Engineering (ICAEE), Dkaka, Bangladesh, pp. 318-322, 2013.

[13] Q. H. Abbasi, M. M. Khan, S. Liaqat, M. Kamran, A. Alomainy et al., "Experimental investigation of ultra widebanddiversity techniques for on-body radio communications," Progress in Electromagnetics Research C (PIERC), vol. 34, pp. 165-181, 2013.

[14] A. Abbas, N. Hussain, M. J. Jeong, J. Park, K. S. Shin et al., "A rectangular notch-band UWB antenna with controllable notched bandwidth and centre frequency," Sensors, vol. 20, no. 777, pp. 1-11, 2020.

[15] K. Y. Mok, Y. C. Rhee and J. H. Yoon, "Design of a pot-shaped monopole antenna with dual band notched characteristics for UWB application," Journal Electromagnetic Engineering and Science, vol. 17, no. 1, pp. 44-49, 2017.

[16] M. Yazdi and N. Komjani, "Design of a band-notched UWB monopole antenna by means of an EBG structure," IEEE Antennas and Wireless Propagation Letters, vol. 10, pp. 170-173, 2011.

[17] S. Qu, J. Li and Q. Xue, "A band-notched ultra wideband printed monopole antenna," IEEE Antennas and Wireless Propagation Letters, vol. 5, pp. 495-498, 2006.

[18] J. Wu and J. Li, "Compact ultra-wideband antenna with 3.5/5.5 GHz dual band-notched characteristic," in Proc. 5th IEEE International Symposium on Microwave, Antenna, Propagation and EMC Technologies for Wireless Communications, Chengdu, China, pp. 446-450, 2013.

[19] A. A. Kadam, A. A. Deshmukh and K. P. Ray, "Slit loaded pentagon shaped ultra wideband antenna for band notch characteristics," in Proc. IEEE Int. Conf. on Electrical, Computer and Communication Technologies (ICECCT), Coimbatore, India, pp. 1-6, 2019. 
[20] W. Ma, W. Ding and Z. Chen, "A novel planar printed antenna with dual band-notch characteristics for UWB applications," in Proc. IEEE 9th Int. Conf. on Communication Software and Networks (ICCSN), Guangzhou, China, pp. 704-707, 2017.

[21] D. Andreuccetti, R. Fossi and C. Petrucci, Dielectric Properties of Body Tissues in the Frequency Range $10 \mathrm{~Hz}$ to 100 GHz. Italian National Research council. 1997. [Online]. Available: http://niremf.ifac.cnr.it/tissprop/. 